\title{
Palatopharyngeus has respiratory activity and responds to negative pressure in sleep apnoeics
}

\author{
I.L. Mortimore, N.J. Douglas
}

Palatopharyngeus has respiratory activity and responds to negative pressure in sleep apnoeics. I.L. Mortimore, N.J. Douglas. CERS Journals Ltd 1996.

ABSTRACT: The intrinsic tongue muscle, genioglossus, and soft palatal muscles, tensor palatini, levator palatini and palatoglossus, are known to exhibit phasic respiratory activity and to respond reflexly to negative pressure in man, which may be important in the maintenance of upper airway patency. We hypothesized that the palatopharyngeus muscle should also have respiratory activity and increased activity in response to negative upper airway pressure.

We have, therefore, examined the palatopharyngeus and the antagonist muscle, levator palatini, in eight awake sleep apnoea patients, using bipolar electromyography during nose- or mouth-breathing in different postures, and with or without application of negative pressure.

Overall, palatopharyngeus and levator palatini demonstrated phasic respiratory activity. Palatopharyngeus demonstrated increased activity in the supine compared to erect posture. Analysis by route of respiration showed palatopharyngeus to be more active in the supine posture when nose-breathing compared to mouth-breathing. Graded negative pressure application caused significant increases in palatopharyngeus and levator palatini activity when applied via the mouth. Nasal negative pressure application caused a nonsignificant trend to increasing palatopharyngeus activity with increasing negative pressure compared to a significant increase for levator palatini.

We conclude that palatopharyngeus and levator palatini demonstrate respiratory activity and reflex activation in response to negative pressure. Palatopharyngeus may, therefore, have a role as an upper airway dilator. The differential response of palatopharyngeus to oral and nasal negative pressure application may be important in the pathogenesis of sleep apnoea.

Eur Respir J., 1996, 9, 773-778.
Respiratory Medicine Unit, University of Edinburgh, Edinburgh, Scotland, UK.

Correspondence: I.L. Mortimore Scottish National Sleep Laboratory Royal Infirmary

Lauriston Place

Edinburgh

EH3 9YW

Scotland

UK

Keywords: Electromyography

levator palatini

palatopharyngeus

sleep apnoea

soft palate

Received: July 311995

Accepted after revision December 281995

This study was supported by the Wellcome Trust.
The upper airway muscles, genioglossus [1], tensor palatini [2], levator palatini and palatoglossus [3], are known to demonstrate predominantly inspiratory phasic activity and to be reflexly activated by upper airway negative pressure in man [3-6]. Furthermore, the activity of palatal muscles changes with route of respiration [3]. These observations suggest that the upper airway muscles play a role in the maintenance of upper airway patency, which may be relevant to the pathogenesis of the sleep apnoea/hypopnoea syndrome (SAHS).

Both genioglossus [1] and palatoglossus [3] are more active in the supine compared to the erect posture, which corresponds to increased retroglossal diameter and maintenance of retropalatal diameter when supine [7]. In addition, genioglossus reflex activation in response to negative pressure has been shown fluoroscopically to increase retroglossal diameter [8]. Reflex activity of genioglossus is also reduced during sleep in normal subjects [9], and sleep deprivation is known to reduce genioglossus activity [10]. These observations may be relevant to upper airway collapse in patients with SAHS, which occurs at the retropalatal/retroglossal level [11-13].

No studies have so far examined the palatopharyngeus with respect to respiratory activity. KUEHN et al. [14] were unable to find muscle spindles in palatopharyngeus and levator palatini, which suggests that the characteristics of these muscles may be different to the other upper airway muscles. However, these observations are at variance with those of Liss [15]; and we have shown levator palatini to behave in the same way as genioglossus and palatoglossus $[1,3]$ in awake subjects. We, therefore, hypothesized that palatopharyngeus should have respiratory activity and be reflexly activated by upper airway negative pressure.

\section{Methods}

\section{Subjects}

Eight male sleep apnoea patients (mean (SEM) age 44 (4) yrs; body mass index $30(2.0) \mathrm{kg} \cdot \mathrm{m}^{-2}$; apnoea/hypopnoea index $51(10.4)$ episodes $\left.\cdot h^{-1}\right)$ were recruited after local Ethics Committee approval and informed consent had been obtained. Subjects took no medication or alcohol on the day of study. 


\section{Electrodes}

The electrodes were made of sterile silver wire (A 5766-36, Cooner Wire Company, Chatsworth, CA, USA) with an uncoated diameter of $0.125 \mathrm{~mm}$ and a Tefloncoated diameter of $0.175 \mathrm{~mm}$. The last $2-3 \mathrm{~mm}$ of the wire was bared and lightly chloridated. The wires were threaded through 23 guage needles and the tip bent over the bevel of the needle to make hooked intramuscular wire electrodes [1]. Electrodes were then sterilized in ethylene oxide for 5 days.

\section{Electrode placement}

After spraying with topical lignocaine, two needles containing electrodes were inserted perorally under direct vision into the palatopharyngeal arch of the pharyangeal fauces on the same side, parallel to the plane of the hard palate, 5-10 $\mathrm{mm}$ apart and $5 \mathrm{~mm}$ deep. Electrode position was confirmed initially in cadavers.

Levator palatini electrodes were placed as described by Hairston and SAUERLAND [2].

\section{Electromyography (EMG) recording}

A grounding electrode was placed on the subject's clavicle. EMG signals were processed by a unity gain bipolar 4 channel alternating current (AC) preamplifier close to the electrodes (Neurolog NL 824, Digitimer Ltd, Welwyn Garden City, Herts, UK) and then further amplified (Isolator NL 820) to give an amplification of 0.1$50 \mathrm{~K}$.

After filtering between $10 \mathrm{~Hz}$ and $2 \mathrm{kHz}$ (NL 125), the signals were rectified and integrated with a time constant of $100 \mathrm{~ms}$ (NL 703). The raw and integrated EMGs were displayed on oscilloscope monitor (Knott Elektronik, Multichannel large screen display SG 4100) and recorded on videotape (JVC HR - D725EK) through an analogue-to-digital (A/D) Video Cassette Recorder (VCR) adapter (model PCM 4/8, Medical Systems Corp., Greenvale, NY, USA). The videotape was subsequently played back through the same VCR adapter and the output printed on a paper printer (Mark 10-1 Thermal Array Corder, Western Graphtec Inc.). A recording was also made of the output from the amplifier system with the input electrodes shorted to obtain a zero reference baseline signal.

\section{Respiration monitoring}

Chest wall movements were monitored using thoracic and abdominal inductance bands displayed on the monitor as well as recorded on videotape.

\section{Application of negative pressure stimuli}

The system of HoRner et al. [4] was modified so that subjects breathed either via a nose mask with an expiratory valve to minimize dead space (approximately 100 $\mathrm{mL}$ ) or via a mouthpiece (dead space $100 \mathrm{~mL}$ ) attached to a circuit open to the atmosphere, such that inspiration occurred through a solenoid pilot actuated spring return valve (Martonair/Beech, B/6S5P/122/M). At end-expiration (functional residual capacity) the solenoid valve was activated to rapidly change $(10 \mathrm{~ms})$ the breathing circuit from the atmosphere to a $50 \mathrm{~L}$ reservoir evacuated to an excess negative pressure of $-100 \mathrm{cmH}_{2} \mathrm{O}$. Spring loaded valves (Vital Signs Inc.) vented excess negative pressure to atmosphere so that subjects were exposed to a square wave of negative pressure for approximately $400 \mathrm{~ms}$. Negative pressures of 2.5, 5, 7.5, 10 and $12.5 \mathrm{cmH}_{2} \mathrm{O}$ were compared to a "dummy stimulus" of $0 \mathrm{cmH}_{2} \mathrm{O}$. Integrated EMG amplitudes were measured $100 \mathrm{~ms}$ after the start of negative pressure application in order to avoid voluntary muscle effects [4].

Negative pressures were monitored at the nose mask and mouthpiece using a micromanometer (Furness Controls Ltd, Bexhill, UK) connected via $136 \mathrm{~cm}$ of tubing, which introduced a delay of $2 \mathrm{~ms}$; 0-90\% response time was $10 \mathrm{~ms}$. Retropalatal and oropharyngeal pressures were monitored using a catheter tip transducer (Gaeltec Ltd, S8b, Skye, Scotland) inserted via the nose with the tip positioned by visual inspection $1 \mathrm{~cm}$ below the uvula, so that during mouth-breathing the tip was below the soft palate and during nose-breathing the tip was located behind the soft palate. This allowed both oropharyngeal (oral-breathing) and nasopharyngeal (nose-breathing) pressures to be measured. All pressure recordings were stored on videotape and transferred to paper for analysis as described above.

\section{Airway resistance}

Upper airway resistance was calculated using the difference between nose mask/mouthpiece pressure and retropalatal/nasopharyngeal pressure at inspiratory and expiratory flows of $15 \mathrm{~L} \cdot \mathrm{min}^{-1}$. Flow was measured using a pneumotachograph. Airway resistance was expressed as $\mathrm{cmH}_{2} \mathrm{O} \cdot \mathrm{L} \cdot \mathrm{s}^{-1}$.

\section{Protocol}

Twenty minutes after the application of lignocaine, maximum EMG amplitudes were recorded for levator palatini and palatopharyngeus by swallowing five times and also by breathing forcefully via the nose with the mouth open (palatopharyngeus), as described by FRITZELL [16].

Subject position was standardized by seating subjects and asking them to look straight ahead (erect) and by lying on a trolley with no head support (supine). Subjects were instructed to breathe "through the mouth only", "through the nose only" and "through the nose only with the mouth open". Noseclips were not used when mouthbreathing.

Data were recorded for at least 30 breaths, with subjects breathing through the nose or mouth both in erect and supine postures. The mean values from these recordings were used in the analysis, in order to allow for breath-by-breath variation. Negative pressure was applied at least 10 times at each negative pressure level and the mean of 10 technically acceptable recordings was used for further analysis. The order of the various manoeuvres (negative pressure application, posture and route) were randomized for each subject in a balanced design.

Recordings were also made during nose-breathing with the mouth open. Absence of oral airflow was verified using a pneumotachograph held at the mouth.

Maximal manoeuvres were repeated at the end of the experiment. 


\section{Analysis of results}

All integrated EMGs were expressed as a percentage of the maximum $[1,17]$ to allow intra- and intersubject comparison. Inspiratory activity quoted was peak integrated EMG during the respiratory cycle (phasic), and expiratory (tonic) EMG activity the lowest value [5]. Integrated EMG values were averaged over at least 30 breaths in both postures and routes. The average integrated EMG for a minimum of 10 negative pressure applications at each level was used for statistical analysis.

The effects of phase of respiration, route and posture on integrated EMGs and airway resistance were compared using repeated measures analysis of variance, and the effects of pressure by one way analysis of variance (ANOVA) and t-tests with Bonferroni corrections where appropriate (Statistical Package for the Social SciencesPersonal Computer (SPSS-PC) package).

Nose mask and mouthpiece pressures were compared with pressures measured with the catheter tip transducer $100 \mathrm{~ms}$ after negative pressure application by paired ttests.

\section{Results}

Phase

Both levator palatini $(\mathrm{F}=11.9 ; \mathrm{p}=0.01)$ and palatopharyngeus $(\mathrm{F}=19.2 ; \mathrm{p}=0.003)$ demonstrated phasic respiratory activity, with higher inspiratory compared to expiratory activity as shown in figure 1 for one subject. The lowest value during the respiratory cycle (tonic activity) occurred during expiration in all eight subjects. The presence of phasic activity was not significantly affected by route or posture for levator palatini $(\mathrm{p}>0.05)$ or palatopharyngeus $(\mathrm{p}>0.05)$, as shown in figure 2 .

\section{Posture}

There was no significant overall effect of change in posture from erect to supine for levator palatini $(\mathrm{F}=4.5$; $\mathrm{p}=0.07)$. Palatopharyngeus demonstrated increased activity in the supine posture overall $(\mathrm{F}=6.26 ; \mathrm{p}=0.04)$ (fig. 2).

Route

Nasal-compared to mouth-breathing (fig. 2) caused no significant change in levator palatini $(\mathrm{F}=0.02 ; \mathrm{p}=0.91)$ or palatopharyngeus activity $(\mathrm{F}=0.05 ; \mathrm{p}=0.83)$ overall. However, analysis of route of respiration by posture showed palatopharyngeus to be more active when nosebreathing supine $(\mathrm{F}=20.6 ; \mathrm{p}=0.003)$ compared to mouthbreathing (fig. 2).

Comparison of nose-breathing with the mouth open and closed

Nose-breathing with the mouth open (fig. 3) caused a significant increase both in levator palatini $(\mathrm{F}=49.4$; $\mathrm{p}<0.001)$ and palatopharyngeus $(\mathrm{F}=10.4 ; \mathrm{p}=0.02)$ activity compared to breathing with the mouth closed.
Levator palatini

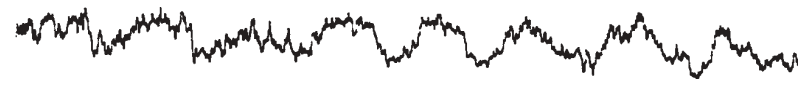

Palatopharyngeus

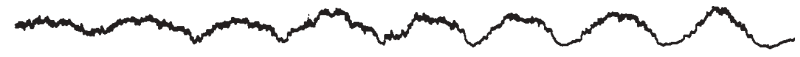

Respitrace

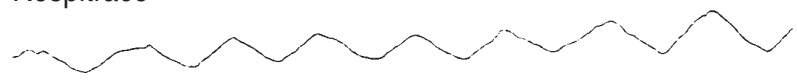

$\uparrow$ Inspiration $\downarrow$ Expiration

Fig. 1. - Integrated electromyographs (EMGs) of levator palatini and palatopharyngeus during mouth-breathing (erect) in one subject. Phase of respiration is shown by respitrace.
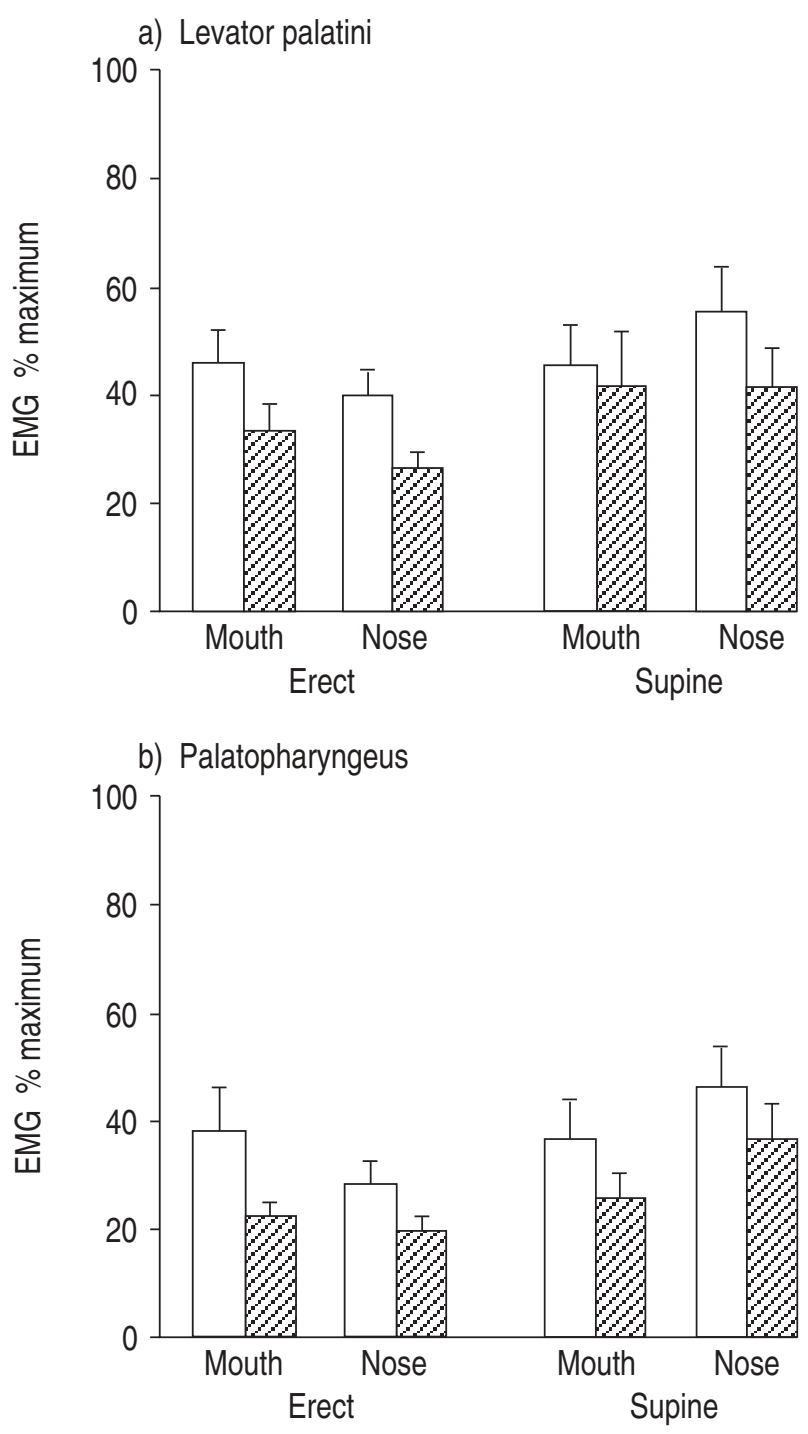

Fig. 2. - Electromyographic (EMG) activity of: a) levator palatini; and b) palatopharyngeus shown for nose- and mouth-breathing both in erect and supine postures for eight SAHS patients. $\square$ : inspiratory (phasic) activity; $\square$ : expiratory (tonic) activity. Values are presented as mean \pm SEM. SAHS: sleep apnoea/hypopnoea syndrome. 


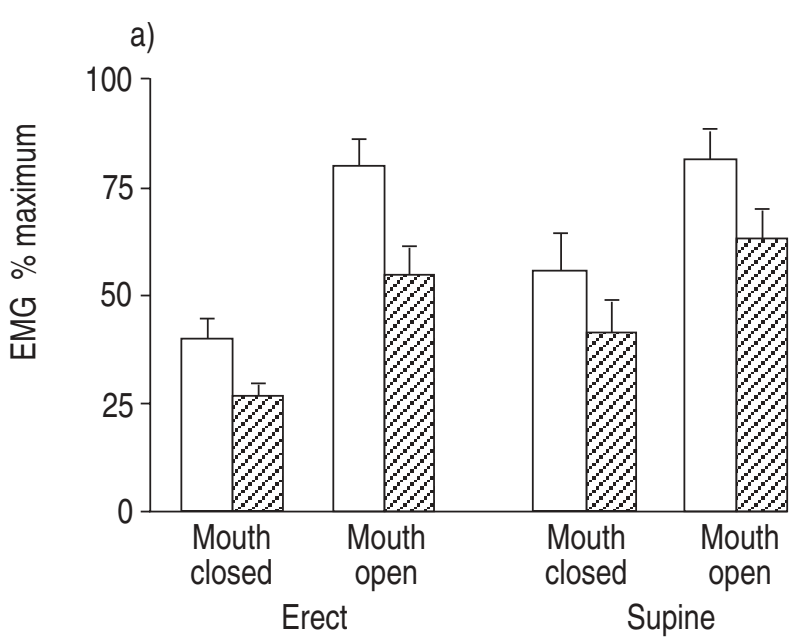

b)

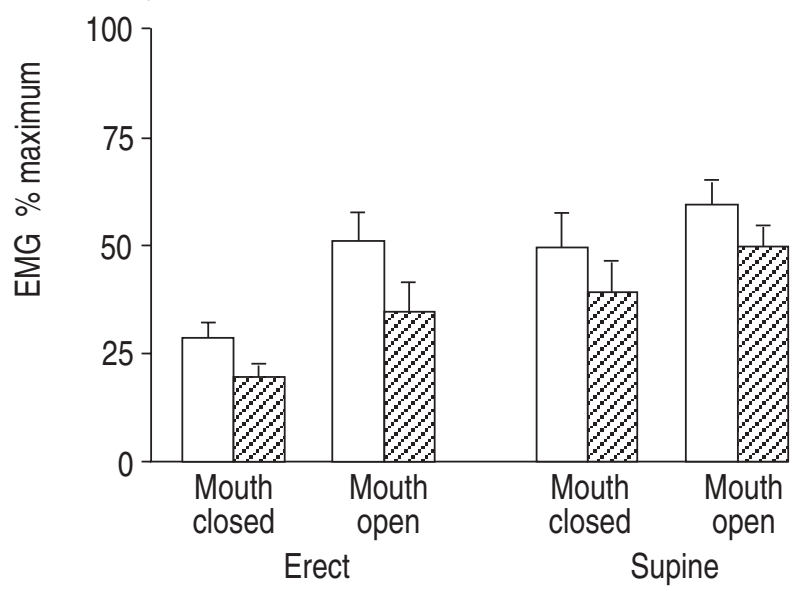

Fig. 3. - Electromyographic (EMG) activity of: a) levator palatini; and b) palatopharyngeus during nose-breathing with the mouth held open and closed both in erect and supine postures for eight sleep apnoea patients. $\square$ : inspiratory (phasic) activity; $\square$ : expiratory (tonic) activity. Values are presented as mean \pm SEM.

\section{Negative pressure application}

The effects of negative pressure application on levator palatini and palatopharyngeus integrated EMGs $100 \mathrm{~ms}$ after the stimulus are shown in figures 4 and 5. There were no significant differences in the negative pressure stimuli applied to the pharynx via the nasal or oral route (table 1).

Reflex levator palatini activity was significantly increased by negative pressure applied via the mouth $(\mathrm{F}=15.3$; $\mathrm{p}<0.001)$ and also via the nose $(\mathrm{F}=3.75 ; \mathrm{p}=0.008)$. When individual negative pressures were compared to the "dummy stimulus" of $0 \mathrm{cmH}_{2} \mathrm{O}$, levator palatini activity was significantly increased by all pressures from -2.5 to -12.5 $\mathrm{cmH}_{2} \mathrm{O}$ when applied via the mouth $(\mathrm{p}<0.01)$, and for pressures from -5 to $-12.5 \mathrm{cmH}_{2} \mathrm{O}$ when applied via the nose $(\mathrm{p}<0.01)$. Palatopharyngeus activity was significantly increased by graded negative pressure applied via the mouth $(\mathrm{F}=3.86 ; \mathrm{p}=0.006)$ but there was only a nonsignificant trend to increasing activity when increasingly negative pressure was applied via the nose $(\mathrm{F}=1.85$; $\mathrm{p}=0.17$ ). Analysis of individual negative pressures compared to the "dummy" stimulus showed a significant difference for all pressures from -2.5 to $-12.5 \mathrm{cmH}_{2} \mathrm{O}$
Levator palatini

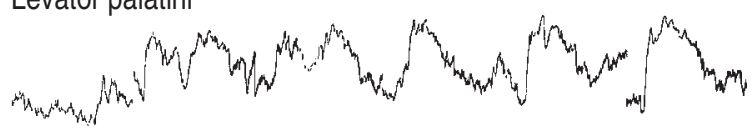

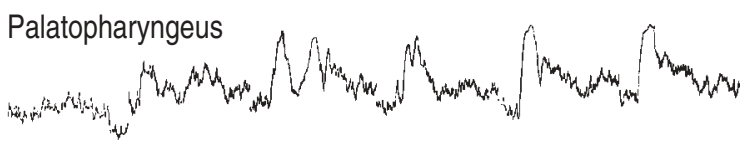

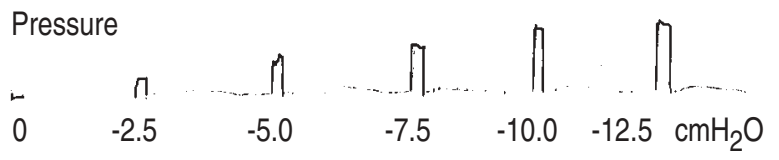

Fig. 4. - Integrated electromyographic (EMG) activity of levator palatini and palatopharyngeus in response to negative pressure applied via the nose in one subject. Negative pressures are measured in $\mathrm{cmH}_{2} \mathrm{O}$ and pressure stimulus duration is approximately $300-400 \mathrm{~ms}$. This is a composite figure and the responses shown are not consecutive.

a)

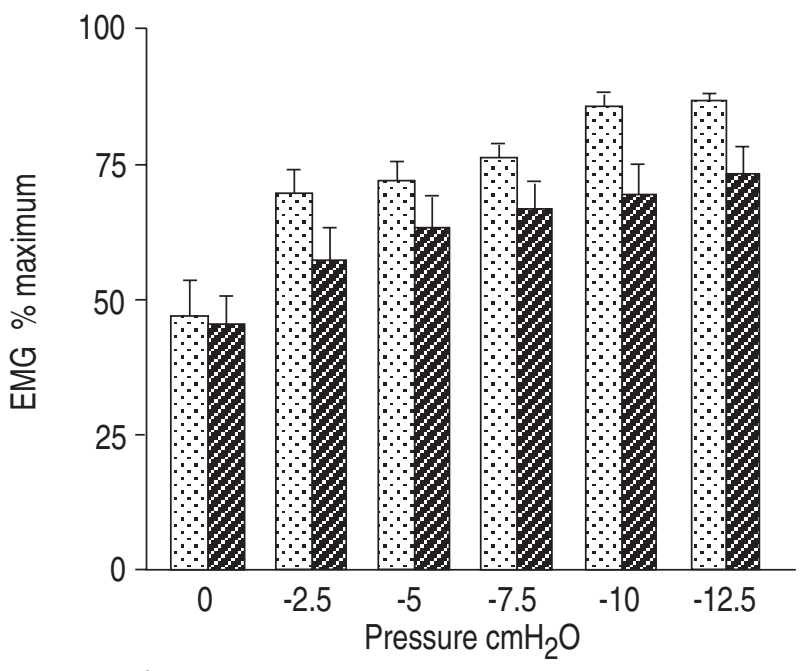

b)

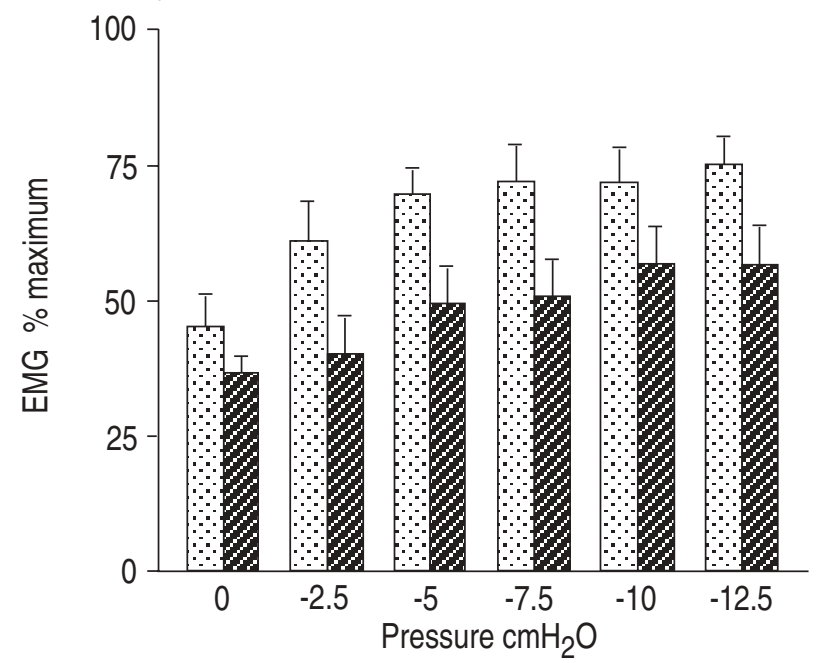

Fig. 5. - Effect of route of negative pressure application on levator palatini ( $\square$ ) and palatopharyngeus ( $\square$ ) integrated electromyographic (EMG) activity. a) Mouth-breathing; b) Nose-breathing. 
Table 1. - Comparison of nasopharyngeal and oropharyngeal pressures measured $100 \mathrm{~ms}$ after negative pressure application at the nose or mouth for eight subjects

\begin{tabular}{ccc}
\hline $\begin{array}{c}\text { Pressure applied } \\
\text { at nose/mouth } \\
\mathrm{cmH}_{2} \mathrm{O}\end{array}$ & $\begin{array}{c}\text { Nasopharyngeal } \\
\text { pressure } \\
\mathrm{cmH}_{2} \mathrm{O}\end{array}$ & $\begin{array}{c}\text { Oropharyngeal } \\
\text { pressure } \\
\mathrm{cmH}_{2} \mathrm{O}\end{array}$ \\
\hline 0 & $-0.1(0.37)$ & $-0.1(0.14)$ \\
-2.5 & $-2.4(0.7)$ & $-2.6(0.42)$ \\
-5.0 & $-4.8(0.45)$ & $-4.8(0.25)$ \\
-7.5 & $-7.1(0.73)$ & $-6.8(0.65)$ \\
-10.0 & $-8.8(1.42)$ & $-8.7(2.0)$ \\
-12.5 & $-10.4(1.73)$ & $-10.4(2.12)$ \\
\hline
\end{tabular}

Values are presented as mean $\pm \mathrm{SD}$.

$(\mathrm{p}<0.002)$ when applied via the mouth. However, when negative pressure was applied via the nose, palatopharyngeus was not activated significantly by pressures of -2.5 ( $>0.05)$ or $-5.0 \mathrm{cmH}_{2} \mathrm{O}(\mathrm{p}>0.05)$.

The increased EMG responses to negative pressures of -2.5 and $-5 \mathrm{cmH}_{2} \mathrm{O}$ applied via the nose were greater for levator palatini compared to palatopharyngeus, both when analysed as a change of percentage maximal EMG activity $(\mathrm{p}<0.05$ and $\mathrm{p}<0.01$, respectively) and when analysed as a percentage change from baseline EMG $(\mathrm{p}<0.002$ and $\mathrm{p}<0.001$, respectively).

\section{Airway resistance}

Upper airway resistance was significantly lower when mouth-breathing compared to nose-breathing $(\mathrm{F}=8.2$; $\mathrm{p}=0.02$ ) and in the erect compared to supine posture $(\mathrm{F}=12 ; \mathrm{p}=0.01)$. Expiration was associated with a lower resistance compared to inspiration $(\mathrm{F}=20.0 ; \mathrm{p}=0.003)$. Mean values are shown in table 2.

\section{Discussion}

Palatopharyngeus and levator palatini both demonstrate respiratory activity and reflex activation in response to upper airway negative pressure application. The respiratory activity of palatopharyngeus is greatest when nose-breathing in the supine posture. These observations suggest that levator palatini and palatopharyngeus may play a role in maintenance of upper airway patency.

EMG activity was expressed as percentage maximum activity to allow inter- and intrasubject comparison [1, 17]. Both for levator palatini and palatopharyngeus the manoeuvre which elicited the greatest activity was swallowing. This manoeuvre proved to be highly reproducible, which is probably reflected by the fact that swallowing is initiated voluntarily but, thereafter, is involuntary.
Manoeuvres such as forced nasal-breathing with the mouth open and saying "aah" [16], which are reported to produce maximal activity, were subject effort-dependent and often produced submaximal and variable results.

SAHS patients were chosen as subjects because palatopharyngeus is not easily accessible and, in our experience, they are more tolerant of palatal muscle electromyography than normal subjects. This may be related to a reduced gag reflex in SAHS patients (our subjective impression) or may be related to the greater oropharyngeal soft tissue mass [18], which makes electrode placement less traumatic. In the present study, the characteristics of levator palatini in SAHS patients were essentially the same as demonstrated previously for normal subjects [3], and palatopharyngeus has been shown, for the first time, to demonstrate phasic respiratory activity and a reflex response to negative pressure.

\section{Spontaneous breathing}

Analysis of spontaneous breathing at rest showed both levator palatini and palatopharyngeus to be inspiratory phasic muscles irrespective of route/posture, which supports upper airway dilating action as one of their roles. Overall, palatopharyngeus was more active in the supine posture when nose-breathing, the situation when airway resistance was highest (table 2). This should, theoretically, help to maintain retropalatal patency by pulling the soft palate anteriorly (against gravity and inspiratory negative pressure). The increased activity of palatopharyngeus in this situation is similar to that of palatoglossus [3]. Thus, palatopharyngeus and palatoglossus are probably acting in concert to maintain retropalatal patency when nose-breathing supine, a position in which the retropalatal space, especially in SAHS patients, is compromised [7]. The larger soft palates of SAHS patients [7] may explain the posterior movement observed in SAHS patients when supine.

Nose-breathing with the mouth held open caused a marked increase in levator palatini and palatopharyngeus activity. During this manoeuvre, palatopharyngeus is probably pulling the soft palate hard against the tongue, as is palatoglossus [3], to stop air leaking into the mouth. The increased activity of levator palatini in this situation may serve to stiffen the soft palate and thus, in conjunction with the increased activity of palatopharyngeus and palatoglossus, may prevent inspiratory posterior movement of the soft palate. However, a relative overactivity of levator palatini EMG activity compared to palatopharyngeus (and possibly palatoglossus) may occur in SAHS and contribute to reduced retropalatal patency. The increased EMG activity when nose-breathing with

Table 2. - Effect of posture, route and phase of respiration on airway resistance $\left(\mathrm{cmH}_{2} \mathrm{O} \cdot \mathrm{L} \cdot \mathrm{S}^{-1}\right)$ measured at $15 \mathrm{~L} \cdot \mathrm{min}^{-1}$ inspiratory (I) and expiratory $(\mathrm{E})$ flow

\begin{tabular}{|c|c|c|c|c|c|c|c|}
\hline \multicolumn{4}{|c|}{ Erect } & \multicolumn{4}{|c|}{ Supine } \\
\hline \multicolumn{2}{|c|}{ Nose-breathing } & \multicolumn{2}{|c|}{ Mouth-breathing } & \multicolumn{2}{|c|}{ Nose-breathing } & \multicolumn{2}{|c|}{ Mouth-breathing } \\
\hline I & E & I & E & I & $\mathrm{E}^{\circ}$ & I & $\mathrm{E}^{\circ}$ \\
\hline $\begin{array}{r}5.1 \\
\pm 3.1\end{array}$ & $\begin{array}{r}2.8 \\
\pm 2.2\end{array}$ & $\begin{array}{r}3.0 \\
\pm 1.7\end{array}$ & $\begin{array}{r}1.7 \\
\pm 1.4\end{array}$ & $\begin{array}{r}8.0 \\
\pm 4.5\end{array}$ & $\begin{array}{r}3.2 \\
\pm 1.1\end{array}$ & $\begin{array}{r}3.5 \\
\pm 2.5\end{array}$ & $\begin{array}{r}1.6 \\
\pm 1.1\end{array}$ \\
\hline
\end{tabular}

Values are presented as mean \pm SD. 
the mouth held open may be a reflex response to mouth opening (muscle stretch) initially, but in awake subjects probably has a significant voluntary (central) component. The results mirror those for levator palatini (and palatoglossus) previously observed in normal subjects [3].

\section{Negative pressure application}

Levator palatini activity was significantly increased by increasing negative pressures from -2.5 to $-12.5 \mathrm{cmH}_{2} \mathrm{O}$, irrespective of route of application (nose/mouth), which is similar to normal subjects [3]. Palatopharyngeus activity was increased by negative pressures from -2.5 to $-12.5 \mathrm{cmH}_{2} \mathrm{O}$ when applied via the mouth. Increasing negative pressure applied via the nose, however, caused only a nonsignificant trend towards increased palatopharyngeus activity. This route-dependent differential response to negative pressure application for palatopharyngeus may compromise upper airway patency because the relative underactivity of palatopharyngeus with nasal negative pressure (fig. 4) may allow the soft palate to be pulled posteriorly by levator palatini, thus compromising an upper airway which is already smaller when compared to normal subjects [7]. KUEHN et al. [19] observed palatal position to correlate best with palatopharyngeus and palatoglossus activity during nonrespiratory manoeuvres, which supports our hypothesis. However, at present, there is no way of knowing for palatal muscles the amount of force generated by each individual muscle, and therefore, the overall effect on palatal position. Thus, further studies combining electromyography with real time soft palate imaging would be helpful in determining the precise roles of the individual muscles in maintenance of upper airway patency.

In summary, palatopharyngeus behaves in a similar manner to genioglossus and the other soft palatal muscles, demonstrating phasic respiratory activity and reflex activity in response to upper airway negative pressure. This suggests several mechanisms which together may compromise the upper airway dilating activity of palatopharyngeus during nasal breathing asleep, thus allowing retropalatal collapse in SAHS patients. Firstly, upper airway muscles probably have a reduced response to negative pressure during sleep [9]. Secondly, soft palatal muscles have a reduced response to negative pressure in SAHS patients compared to normals [20]. Thirdly, palatopharyngeus appears to demonstrate a route-dependent response to negative pressure, such that activity is relatively lower in response to nasal compared to oral negative pressure, which is a similar response to that observed for palatoglossus in normals [3]. A narrow upper airway [7] combined with the above factors could, thus, contribute to retropalatal collapse during sleep in patients with SAHS.

\section{References}

1. Douglas NJ, Jan MA, Yildirim N, Warren PM, Drummond GB. The effect of posture and breathing route on genioglossal electromyogram activity in normal subjects and in patients with the sleep apnea/hypopnea syndrome. Am Rev Respir Dis 1993; 148: 1341-1345.
2. Hairston LE, Sauerland EK. Electromyography of the human palate: discharge patterns of the levator and tensor veli palatini. Electromyogr Clin Neurophysiol 1981; 21: 287-297.

3. Mortimore IL, Mathur R, Douglas NJ. Effect of posture, route of respiration and negative pressure on palatal muscle activity in man. J Appl Physiol 1995; 79: 448-454.

4. Horner RL, Innes JA, Guz A. Evidence for reflex pharyngeal airway dilator muscle activation by sudden negative airway pressures in man. J Physiol (Lond) 1991; 436: 15-29.

5. Wheatley JR, White DP. Influence of sleep on genioglossus EMG reflex response to negative pressure in normal subjects. Am Rev Respir Dis 1992; 145: A212.

6. Wheatley JR, Tangel DJ, Mezzanotte WS, White DP. Influence of sleep on response to negative pressure of tensor palatini and retropalatal airway. J Appl Physiol 1993; 75: 2117-2124.

7. Yildirim N, Fitzpatrick MF, Whyte KF, Jalleh R, Wightman AJA, Douglas NJ. The effect of posture on upper airway dimensions in normal subjects and in patients with the sleep apnea/hypopnea syndrome. Am Rev Respir Dis 1991; 144: 845-847.

8. Kobayashi I, Perry A, Rhymer J, et al. Relationship between the electrical activity of genioglossus muscle activity and the upper airway patency: a study in laryngectomised subjects. Am J Respir Crit Care Med 1994; 149: A148.

9. Horner RL, Innes JA, Morrell M, Shea SA, Guz A. The effect of sleep on reflex genioglossus muscle activation by stimuli of negative airway pressure in humans. $J$ Physiol (Lond) 1994; 476: 141-151.

10. Leiter JC, Knuth SL, Bartlett D. The effect of sleep deprivation on the activity of the genioglossus muscle. Am Rev Respir Dis 1985; 132: 1242-1245.

11. Hudgel DW. Variable site of airway narrowing among obstructive sleep apnea patients. J Appl Physiol 1986; 61: 1403-1409.

12. Shephard JW, Thawley SE. Localization of upper airway collapse during sleep in patients with obstructive sleep apnea. Am Rev Respir Dis 1990; 141: 1350-1355.

13. Stein MG, Gamsu G, De Greer D, Golden JA, Crumley RL, Webb WR. Cine CT in obstructive sleep apnea. Am J Radiol 1987; 148: 1069-1074.

14. Keuhn DP, Templeton PJ, Maynard JA. Muscle spindles in the velopharyngeal musculature of humans. $J$ Speech Hearing Res 1990; 33: 488-493.

15. Liss JM. Muscle spindles in the human levator veli palatini and palatoglossus muscles. J Speech Hearing Res 1990; 33: 736-746.

16. Fritzell B. Electromyography in the study of velopharyngeal function: a review. Folia Phoniat 1979; 31: 93-102.

17. Mezzanotte WS, Tangel DJ, White DP. Waking genioglossal electromyogram in sleep apnea patients versus normal controls (a neuromuscular compensatory mechanism). J Clin Invest 1992; 89: 1571-1579.

18. Stauffer JL, Buick MK, Bixler EO, et al. Morphology of the uvula in obstructive sleep apnea. Am Rev Respir Dis 1989; 140: 724-728.

19. Kuehn DP, Folkins JW, Cutting CB. Relationships between muscle activity and velar position. Cleft Palate J 1982; 19: 25-35.

20. Mortimore IL, Douglas NJ. Comparison of palatal muscle reflex activity in sleep apnea patients and nonsnoring subjects. Am J Respir Crit Care Med 1995; 151: A557. 